\title{
'||||||||||||||||||||||||||||||||||||||||||||||||||||||||||||||||||||||.
}

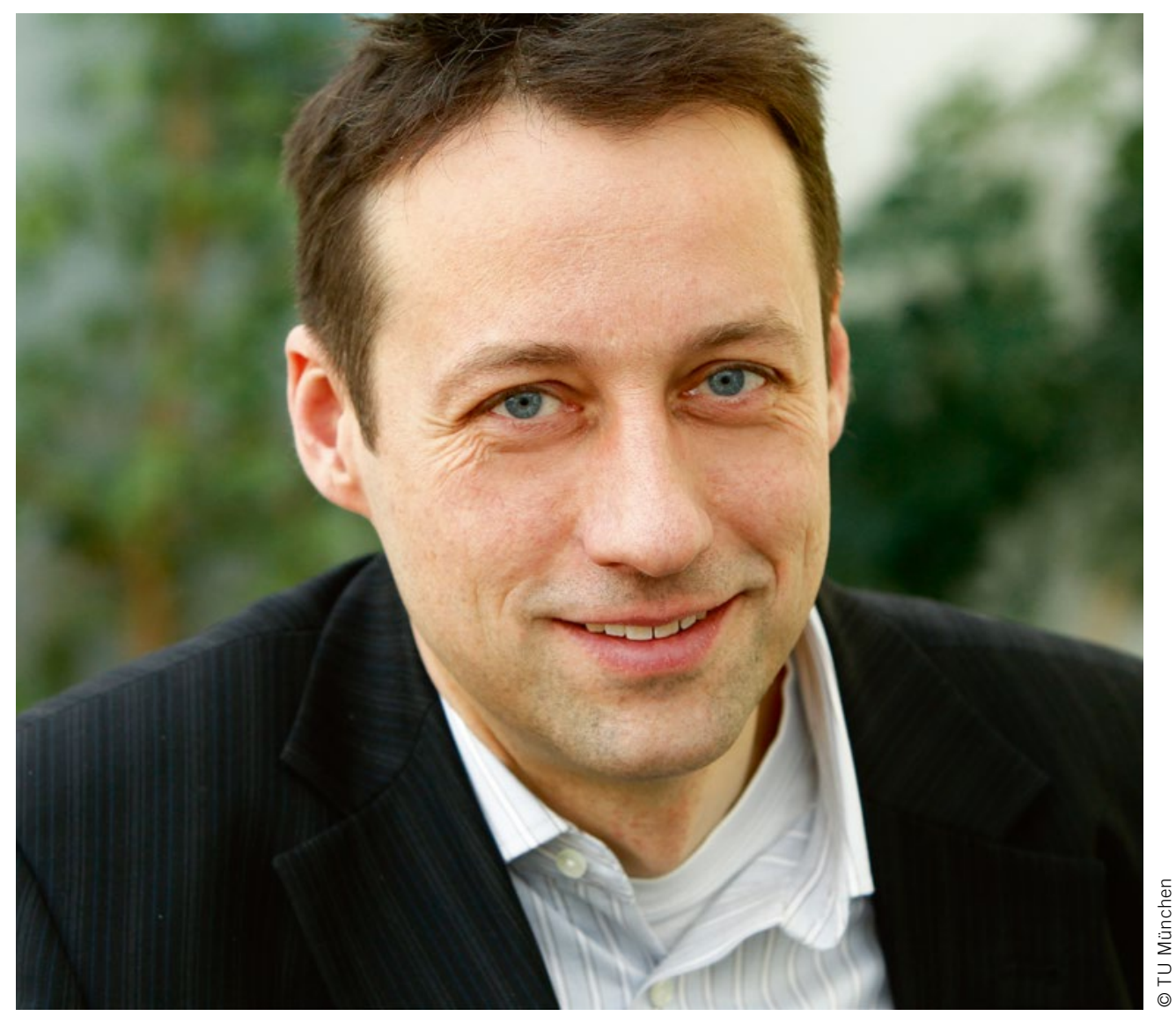

Prof. Dr.-Ing. Markus Lienkamp Lehrstuhl für Fahrzeugtechnik, Technische Universität München

\section{Geld schießt Tore}

An den Universitäten ist es nicht anders als im Fußball: Mit viel Geld kann man eine moderne Ausstattung kaufen, hochkarätige Professoren anwerben und damit hochwertige Forschung und gute Lehre machen.

Die TU München gehört sicher zu den am besten ausgestatteten Universitäten in Deutschland und hat deshalb die letzten Jahrzehnte eine sehr gute Entwicklung auch in internationalen Rankings genommen. Dennoch verfügen wir nur über ein Drittel der Grundausstattung je Student einer ETH Zürich. Und das Massachusetts Institute of Technology (MIT) kann mit dem achtfachen Budget aufwarten. Die gesamte Exzellenzinitiative für alle deutschen Universitäten über fünf Jahre liegt in der Höhe des Jahresbudgets von Stanford. Wie können wir so in der Champions League mitspielen?

In der Vergangenheit ist dies gelungen, weil Professoren zusätzlich zu der unzureichenden Grundfinanzierung durch die Länder nicht zuletzt auch industrielle Drittmittel in großem Umfang eingeworben haben. Damit konnten zusätzliche Mitarbeiter und Assistenten eingestellt werden, die speziell die Forschung entscheidend verstärkt haben. Die Themen wurden vom Lehrstuhl definiert und haben die Lehrstuhlkompetenz gefördert. Die hervorragend ausgebildeten promovierten Ingenieure sitzen heute in den Vorstandsetagen der OEM und Zulieferer.

Seit etlichen Jahren stelle ich mit vielen anderen Kollegen fest, dass sich bei immer mehr großen Firmen die Grundstimmung geändert hat: Bei exakter Nutzenbetrachtung erscheint der firmeninterne Doktorand günstiger: Es fällt kein Overhead oder gar IP-Zuschlag der Universität an, der Doktorand kann sich einzig und allein auf die Forschung konzentrieren. Das Thema kann direkt vorgegeben werden. Der Doktorand sieht nur Vorteile, die Firma ebenso und es finden sich offensichtlich immer noch genug Kollegen für die Betreuung. Dass die Universitäten damit massiv verlieren, scheint keinem der Beteiligten klar zu sein oder wird einfach nur hingenommen.

Deshalb haben wir mit einigen Betroffenen und Beteiligten einen offenen Brief mit dem Titel „Die Industriepromotion Regeln guter wissenschaftlicher Praxis“ dazu formuliert. Die Stellungnahme wurde Mitte Februar vom Deutschen Hochschulverband veröffentlicht - in der Hoffnung, dass Firmen und Beteiligte zum Nachdenken kommen. Ich würde mich freuen, wenn sich immer mehr Kollegen unserer Sichtweise anschließen. 